\title{
Cellular distribution of CD44 gene transcripts in colorectal carcinomas and in normal colonic
}

\section{mucosa}

\author{
H Gorham, T Sugino, A C Woodman, D Tarin
}

\begin{abstract}
Aim-To study the cellular distribution of CD44 mRNA transcripts in tissue sections of colorectal cancer and corresponding normal colonic mucosa in order to correlate the findings with information from immunohistochemical methods and previous data from analysis by reverse transcription- polymerase chain reaction (RT-PCR).

Methods-In situ hybridisation (ISH) analysis of CD44 standard (CD44s) and variant (CD44v) mRNA in cryostat sections of normal and neoplastic colonic mucosa with ${ }^{35} \mathrm{~S}$-labelled riboprobes. Immunohistochemistry was performed on cryostat sections from the same patients using monoclonal antibodies directed against epitopes encoded by CD44 exon 1 (F.10.44.2), exon 5, (Hermes 3), exon 7 (23.6.1), and exon 11 (2F10).
\end{abstract}

Results-CD44s and CD44v transcripts were both strikingly increased in carcinomas compared with corresponding normal mucosa and the abundant CD44v transcripts in tumour tissues were localised exclusively in the cancer cells. CD44s transcripts were present in cancer, inflammatory and resident stromal cells, but the relative amount in carcinoma cells was greater. Immunohistochemical staining broadly paralleled these results, but some clumps of tumour cells showed clear heterogeneity with regard to $\mathrm{CD} 44$ protein content. There were also some scattered focal discrepancies in the quantity and distribution of mRNA transcripts and proteins, respectively.

Conclusions-The ISH technique provides powerful independent corroboration of elevated CD44 gene expression and disproportionately high transcription of CD44v isoforms in carcinoma cells observed in earlier immunohistochemical and RT-PCR studies. It unequivocally localises the abnormally elevated gene transcription within the cancer cells and not in the surrounding inflammatory cells.

(F Clin Pathol 1996;49:482-488)

Keywords: CD44, in situ hybridisation, immunohistochemistry, colonic carcinoma.

The transmembrane glycoprotein CD44 is a cell surface molecule implicated in a number of diverse cell-cell and cell-matrix interactions, including lymphocyte homing, haemopoiesis, cell migration, and possibly tumour metastasis. ${ }^{12}$ The numerous functions of this single gene reflect the complexity of its genomic structure: analysis of the human CD44 gene has determined that there are at least 20 exons distributed over a length of about 60 kilobases on chromosome $11 \mathrm{p} 13$. Between exons 5 and 16 of the genomic template there are at least 10 exons which can be subject to alternative splicing. ${ }^{34}$ Thus, in addition to the "standard" $85-95 \mathrm{kD}$ isoform (CD44s), encoded by the constitutively expressed exons $1-5$ and 16-20, several larger isoforms exist, generated by the insertion of various sections encoded by the "variant" (CD44v) exons into the standard polypeptide backbone and by post-translational glycosylation.

Little is known about the regulation of production of $\mathrm{CD} 44 \mathrm{v}$ isoforms or the functions of CD44v containing molecules. Disorderly overexpression of numerous CD44v containing isoforms seems to be associated with the onset of neoplasia in many tissues ${ }^{56}$ and to increase with tumour progression..$^{7-9}$ Elevated CD44 expression has also been observed in metastastic deposits ${ }^{5}$ and data from animal experiments have suggested that overexpression of isoforms containing exon $11(\mathrm{v} 6)$ could be mechanistically involved in the metastatic process. ${ }^{10}$

Until recently, the identification of cells expressing CD44 has depended heavily on the use of immunohistochemical techniques ${ }^{811}$ and on reverse transcription-polymerase chain reaction (RT-PCR) analysis. Immunohistochemistry permits insights into the quantity and distribution of CD44 proteins in cells and tissues, whilst information on the levels of CD44 mRNA in the sample can be determined by RT-PCR. However, the latter technique necessitates the destruction of cell and tissue organisation to extract the mRNA and the histological and cellular distribution of transcripts and their relation to the distribution and quantity of related CD44 proteins is therefore not revealed. Equally, immunohistochemical localisation of the cellular distribution of CD44 proteins can be affected by conformational accessibility of the relevant epitopes, which may in turn be modified by post-translational modifications or fixation protocols. Therefore, analysis of the histological localisation of gene transcription by in situ hybridisation provides a valuable link for unifying information obtained by the other methods and for obtaining a 


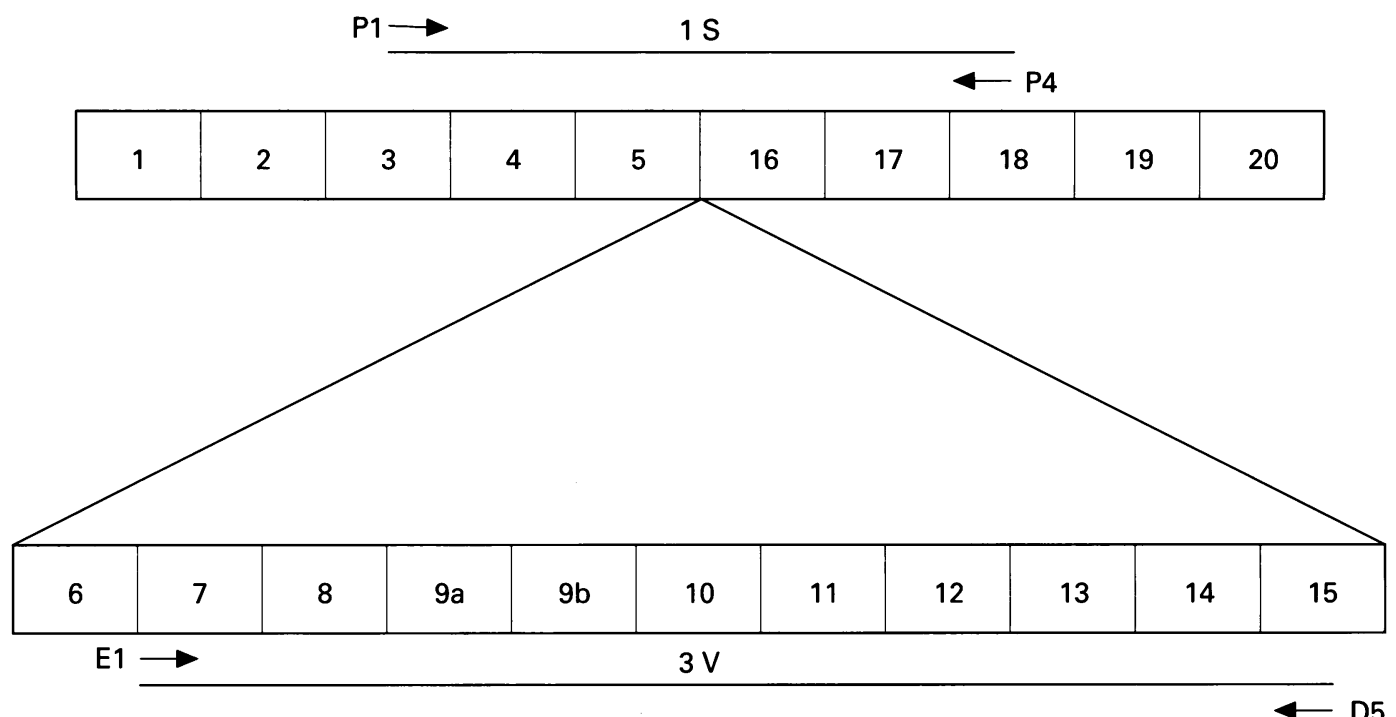

Sequences of CD44 amplification primers

P1 GAC ACA TAT TGC TTC AAT GCT TCA GC

P4 GAT GCC AAG ATG ATC AGC CAT TCT GGA A

E1 TTG ATG AGC ACT AGT GCT ACA GCA

D5 TTC CTT CGT GTG TGG GTA ATG AGA

Figure 1 Schematic representation of the structure of standard and variant CD44 riboprobes.

meaningful picture of CD44 gene expression in neoplasia. In this report we describe new observations with this technique on tumours of the colon.

\section{Methods}

SPECIMEN COLLECTION

Tissue samples from 10 carcinomas, two adenomas and 12 corresponding areas of unaffected mucosa in the same patients were collected within 30 minutes of resection and were snap-frozen in liquid nitrogen.

\section{IN SITU HYBRIDISATION}

In situ hybridisation was carried out by using a modification of the method of Simmons et al ${ }^{12}$ using single stranded ${ }^{35} \mathrm{~S}$-labelled RNA probes. Cryostat sections $(10 \mu \mathrm{m})$ were mounted onto silane treated slides and stored at $-20^{\circ} \mathrm{C}$ until use. Slides were rinsed twice in phosphate buffered saline (PBS), dehydrated through an increasing graded ethanol series to $95 \%$ and then stored at $4^{\circ} \mathrm{C}$. Fixed sections were digested with $0.001 \%$ proteinase $\mathrm{K}$ (Boehringer Mannheim) at $37^{\circ} \mathrm{C}$ for three minutes, rinsed in $0.2 \%$ glycine, post-fixed in $4 \%$ paraformaldehyde for five minutes, rinsed in $0.1 \mathrm{M}$ triethanol amine (TEA), and acetylated in $0.25 \%$ acetic anhydride for 10 minutes at room temperature. Slides were finally rinsed in $2 \times$ SSC (standard saline citrate) and dehydrated in a graded series of ethanol solutions. Sections were dried for at least two hours before being hybridised overnight in a solution of $50 \%$ formamide, $10 \%$ dextran sulphate, $0.3 \mathrm{M} \mathrm{NaCl}, 10 \mathrm{mM}$ Tris pH 8.0, $1 \times$ Denhardt's solution, $0.5 \mathrm{mg} / \mathrm{ml}$ tRNA, and 10 $\mathrm{mM}$ DTT, with $1 \times 10^{6} \mathrm{cpm} / \mathrm{ml}{ }^{35} \mathrm{~S}$-labelled single stranded RNA probe at $50-60^{\circ} \mathrm{C}$. Sections were washed in $4 \times \mathrm{SSC}$, digested with $20 \mu \mathrm{g} / \mathrm{ml} \mathrm{RNase} \mathrm{A}$ at $37^{\circ} \mathrm{C}$ for 30 minutes, then washed at a final stringency of $0.1 \times$ SSC at $60^{\circ} \mathrm{C}$ for 30 minutes and dehydrated in a series of ethanols and dried. Slides were handdipped in Kodak NTB-2 emulsion and then exposed at $4^{\circ} \mathrm{C}$ for two weeks. After being developed, sections were stained with haematoxylin and eosin, mounted and photographed.

PREPARATION OF RNA PROBES FOR IN SITU HYBRIDISATION

Probe for the standard form of CD44 (fig 1)

The RNA probe (riboprobe) for the detection of the standard form of CD44 was synthesised from plasmid pBSIS, comprising a 485 base pair (bp) fragment amplified by PCR from cDNA of human peripheral blood lymphocytes and cloned in pBluescript SK+ (Stratagene).

Oligonucleotides P1 and P4 (fig 1) were used to amplify the standard region CD44 insert in this vector. pBSIS was linearised using $\mathrm{Xba} 1$ prior to synthesis of antisense riboprobe from the T3 promoter or with HindIII for synthesis of sense riboprobe from the T7 promoter.

Probe for the variant forms of CD44 (fig 1)

A 1.1 kilobase DNA fragment containing the complete variant region of CD44 was amplified by PCR using oligonucleotides E1 and D5 from total cDNA isolated from the breast carcinoma cell line ZR75-1 (ATCC CRL 1500). The isolated fragment was cloned into pBluescript SK+ (pBS3V). pBS3V was linearised with HindIII for antisense riboprobe synthesis from the T7 promoter and Xbal for sense riboprobe synthesis from the T3 promoter.

The cloned fragments from pBSIS and pBS3V were sequenced to determine their ori- 
entation and to confirm the absence of intron sequences before probe synthesis.

Radiolabelled antisense and sense riboprobes were generated using a Stratagene RNA transcription kit, incorporating $\left[{ }^{35} \mathrm{~S}\right]-\mathrm{UTP}$ $(>1000 \mathrm{Ci} / \mathrm{mmol}$ ) (Amersham International, Amersham, UK). The radioactively labelled riboprobes were purified using Sephadex G-50 columns (Nickcolumns, Pharmacia). The length and quality of the probe was verified by electrophoresis using a polyacrylamide sequencing gel.

\section{IMMUNOHISTOCHEMISTRY}

Sections, $10 \mu \mathrm{m}$ thick, of snap-frozen histological samples were cut and dried on silane treated slides for at least one hour at room temperature. After being fixed in cold methanol for 10 minutes, slides were air dried and stored at $-20^{\circ} \mathrm{C}$. Non-specific binding of the primary antibody was blocked by incubating slides in normal rabbit serum $(20 \% \mathrm{v} / \mathrm{v})$ in Tris buffered saline (TBS) ( $\mathrm{pH} \mathrm{7.6)}$ for 45 minutes at $37^{\circ} \mathrm{C}$. The serum was removed and primary antibody diluted 1 in 50 in 1\% normal rabbit serum, in TBS, was added and incubated at $4^{\circ} \mathrm{C}$ overnight and then $37^{\circ} \mathrm{C}$ for 30 minutes. Monoclonal antibodies directed against epitopes encoded by various CD44 exons were obtained as follows: F10-44-2 (exon 1; Boehringer Mannheim); Hermes 3 (exon 5; a gift of Dr E C Butcher) ${ }^{13}$; monoclonal antibody 23.6.1 (exon 7; raised by ourselves in collaboration with Boehringer Mannheim) ${ }^{14}$; $2 \mathrm{~F} 10$ (exon 11 ; R and D Systems). Additionally, monoclonal antibody 23.6.1 preabsorbed with antigen ( 30 minutes at room temperature) and non-immune mouse IgG (Sigma, Poole, Dorset, UK) were used as negative controls to exclude the possibility of non-specific reactions. Slides were washed three times in TBS and non-specific peroxidase activity blocked by $3 \%$ hydrogen peroxide in $100 \%(\mathrm{v} / \mathrm{v})$ methanol for 10 minutes. After rinsing in TBS, biotinylated rabbit anti-mouse IgG (Dako, High Wycombe, UK), diluted 1 in $400(\mathrm{v} / \mathrm{v})$ in $1 \%$ (v/v) normal rabbit serum in TBS, was added for two hours at room temperature. After washing in TBS, horseradish peroxidaseABComplex (Dako) was added according to manufacturer's instructions for one hour at room temperature, followed by 30 minutes incubation with $30 \mathrm{mg} \mathrm{3,3'-diaminobenzidine}$ tetrahydrochloride (DAB) (Sigma) and $5 \mu \mathrm{l}$ $\mathrm{H}_{2} \mathrm{O}_{2}(30 \% \mathrm{v} / \mathrm{v})$ in $50 \mathrm{ml}$ TBS. After washing with water, the slides were lightly counterstained with haematoxylin and mounted.

\section{Results}

GENERAL OBSERVATIONS

In initial experiments (data not shown) it was found that the minimum post-hybridisation exposure time to obtain reproducible results and an acceptable background signal with this isotopic labelling system, was two weeks. Attempts to visualise CD44 transcripts with non-isotopic in situ hybridisation methods were unsuccessful although simultaneous efforts to visualise transcripts of other genes, such as lysozyme, succeeded. This information indicates that the copy number of CD44 mRNA is low, even in tumours. However, as is shown below, these mRNA transcripts can be detected with the more sensitive isotopic labelling method and the levels are strikingly increased in the malignant cells relative to normal counterparts in matched samples from the same patient.

\section{NORMAL COLONIC MUCOSA}

Standard CD44 mRNA, as visualised by the $485 \mathrm{bp}$ riboprobe, was easily detected within germinal centres and in lymphocytes, macrophages and plasma cells in the lamina propria of normal colonic mucosa. Low level expression of CD44s mRNA was detected within the epithelial cells lining the bases of the crypts (figs $2 \mathrm{a}$ and $2 \mathrm{~b}$ ) and stromal fibroblasts. Immunohistochemical staining with a monoclonal antibody directed against CD44s protein (Hermes 3 ), corresponded closely to the distribution of CD44s mRNA (fig 3a). Lymphocytes and fibroblasts were strongly stained and some reactivity was localised in the epithelial cells at the bases of the crypts but not in the upper regions of the glands nor in the luminal epithelium.

CD44v mRNA could not be detected in the mucosal germinal centres, infiltrating lymphocytes nor connective tissue fibroblasts (fig 2c). Nor were such transcripts detectable in any epithelial cells. Immunohistochemical observations with monoclonal antibodies directed against epitopes encoded by exons 7 and 11 showed no staining in lymphocytes or other stromal cells but weak staining for the exon 11 epitope was detectable in epithelial cells in the bases of the crypts. This epithelial reactivity was weaker than that seen with the Hermes 3 monoclonal antibody directed against CD44s (see earlier).

\section{COLONIC TUMOURS}

CD44s mRNA was strikingly elevated in the epithelial cells of all adenomas and infiltrating carcinomas examined (figs $4 \mathrm{a}-4 \mathrm{~d}$ ). Although the amount of signal observed over carcinoma cells was greater than that over adenomatous epithelium, it was not possible to detect any meaningful associations between signal intensity and Dukes' staging of colonic carcinoma. The intensity of signal over malignant glands and invading clumps of carcinoma cells was much greater than over inflammatory cells and fibroblasts in the intervening stroma of the tumour, but where such reactive cells congregated some increase in signal relative to normal mucosa was seen as a result of increased cellularity. Immunohistochemical reactivity of CD44s monoclonal antibody with adenoma and carcinoma cells and with the intervening stroma was generally raised (figs $3 b$ and $3 f$ ) but some deeply invading malignant glands were either only weakly stained or completely negative. Sometimes staining with another standard form monoclonal antibody (F10.44.2) could be clearly observed over corresponding areas of a serial section from the same tumour but in general they remained negative. However, in tumours which had such focal negative staining 


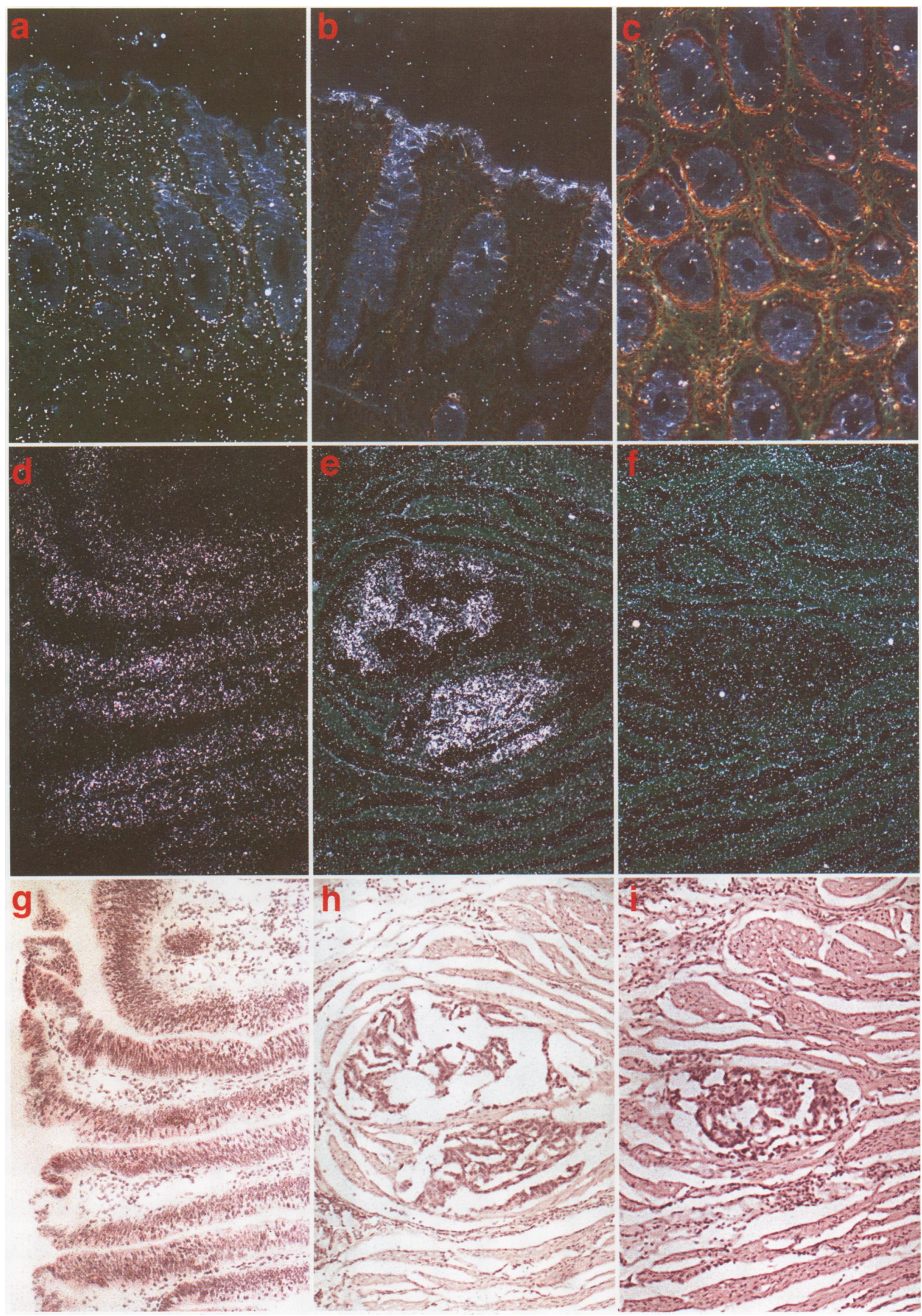

Figure 2 Frozen sections of normal colonic mucosa $(a-c)$ studied by in situ hybridisation illustrating the presence of CD44s mRNA transcripts in basal crypts, infiltrating lymphocytes and macrophages. Plates (a) and (b) hybridised with CD44s antisense and sense riboprobes, respectively. In comparison, the CD44v antisense riboprobe gave minimal signal (c). (Darkfield images, magnification $\times 430$.) Plate (d) shows a darkfield image of colonic adenoma hybridised with CD44v antisense riboprobe showing increased signal compared with normal colonic mucosa. Plate (g) shows the corresponding brightfield image. Plates $(e)$ and $(f)$ show darkfield images of colonic carcinoma hybridised with CD44v antisense and sense riboprobes, respectively, the elevated signal located over carcinoma cells relative to normal colonic epithelium (c) and to surrounding non-malignant cells being clearly demonstrated. Plates ( $h$ ) and (i) are corresponding brightfield images (magnification $\times 215$ ). 
patterns the level of CD44 mRNA transcripts was always generally elevated in the carcinoma cells as a whole.

CD44v mRNA transcripts were also increased in carcinoma cells (figs $2 \mathrm{~d}-2 \mathrm{i}$ ). Again,
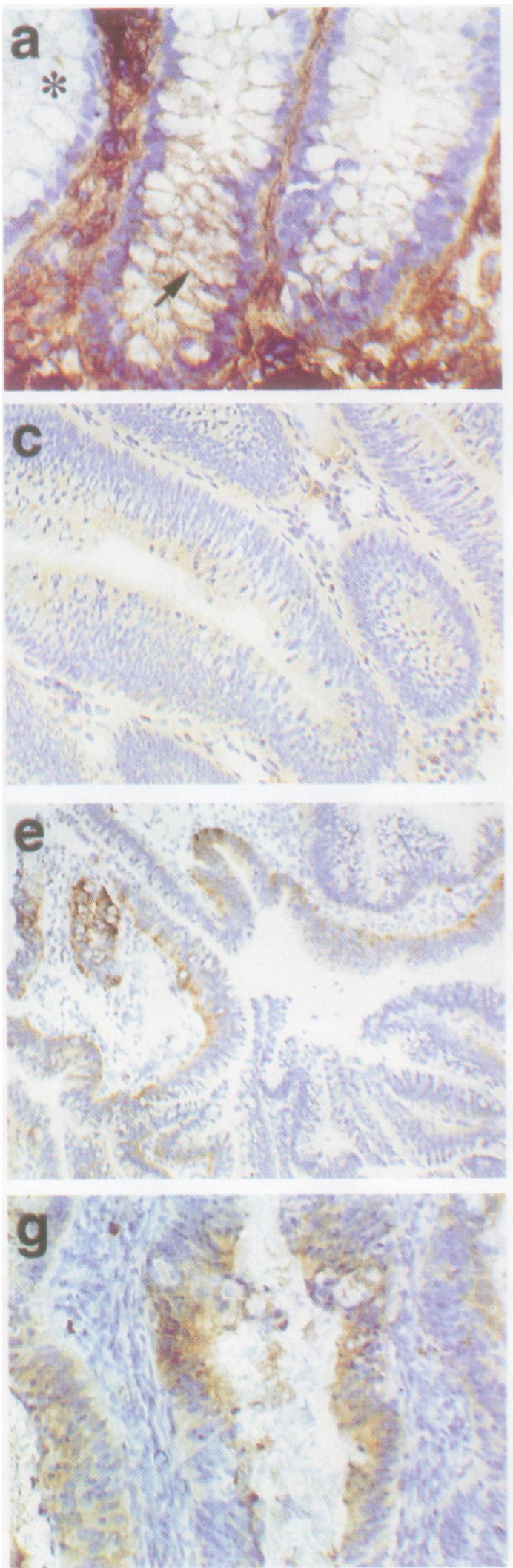

Figure 3 Frozen sections of normal colon (a), adenoma $(b-e)$ and colonic carcinoma $(f-h)$ tissues studied by immunohistochemistry. Plate (a) shows epithelial membrane staining in cells of the basal portions of a normal mucosal crypt with the antibody which recognises the standard form epitope encoded by exon 5 (Hermes 3). Plates (b), (c) and (e) show increased diffuse cytoplasmic staining of neoplastic epithelial cells in tissues from a patient with an adenoma of the show increased diffuse cytoplasmic staining of neoplastic epithelial cells in tissues from a patient with an adenoma of the $(2 F 10)(e)$. Plate $(d)$ shows adenoma stained with monoclonal antibody 23.6.1 which had been preabsorbed with antigen. Plates $(f-h)$ show strong membranous and cytoplasmic staining of colonic carcinoma cells in sections stained with antibodies directed against epitopes encoded by exons 5 (Hermes 3) (f), 7 (23.6.1) (g) and 11 (2F10) (h) (arrows). Magnifications. plates $(a)$ and $(g) \times 420$; plates $(b-d)$ and $(f) \times 200$; plates $(e)$ and $(h) \times 50$.

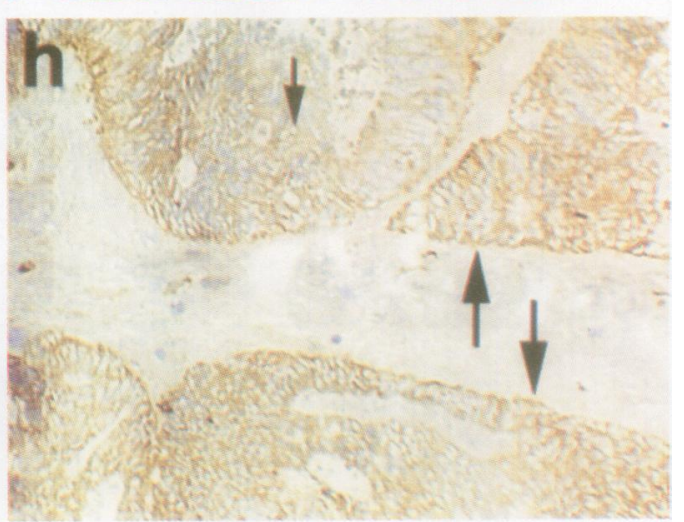

as in the case of CD44s described above, the mount of signal observed over carcinoma cells greater than that over adenomatous pithelium. As virtually no signal was observed
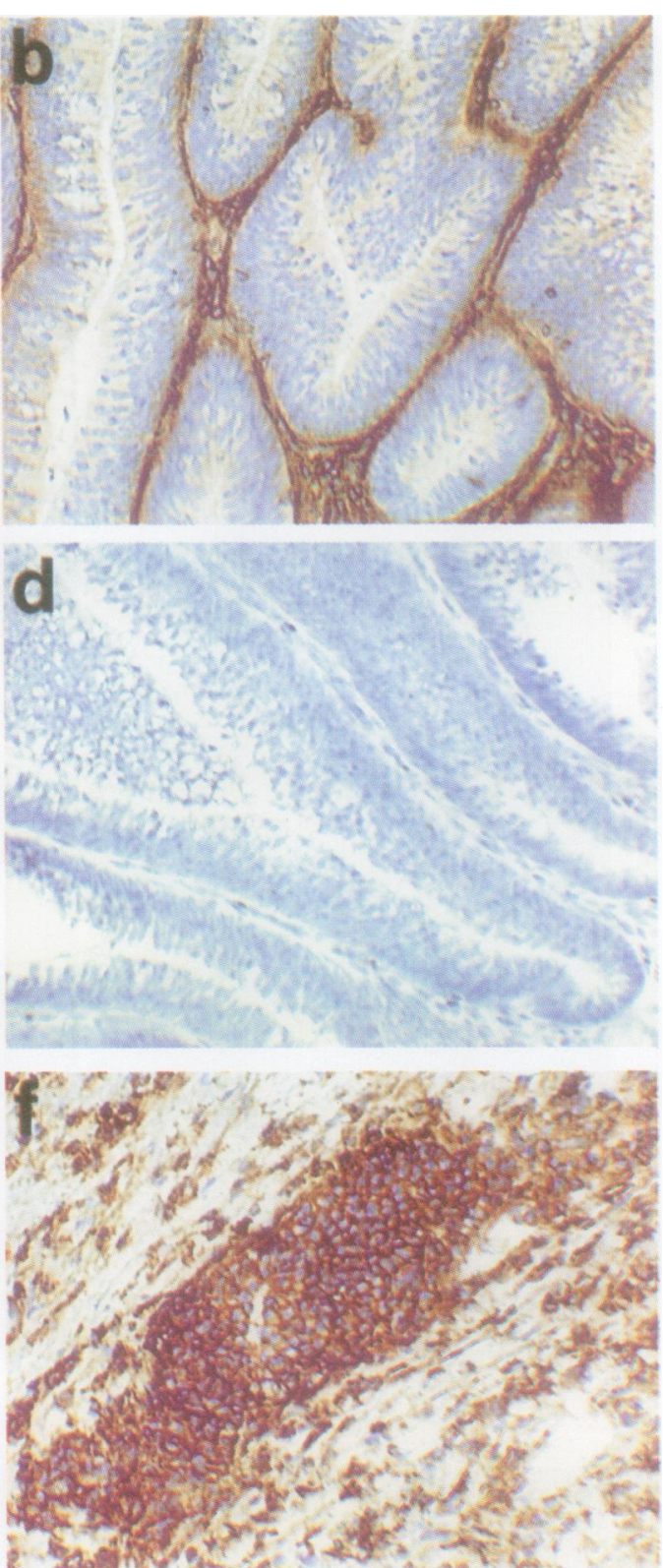
sels and infiltrating inflammatory cells, the differences between neoplastic and normal cells were very striking. Image analysis indicated that it was of the order of 2.5 to 3 times for carcinomas. The distribution of the labelled CD44v probe over the malignant cells was discrete and sharply localised, leaving no uncertainty that the increased transcriptional activity of the CD44v region occurs specifically in the carcinoma cells and not in the reactive ones (for example, lymphocytes). Immunohistochemical staining with monoclonal antibodies directed against exons 7 and 11 encoded epitopes both mirrored the general pattern of mRNA distribution (figs $3 c-3 e, 3 g$, and $3 h$ ), although, once again, some carcinoma glands and clumps of tumour cells did not stain with these antibodies. This is a manifestation of tumour heterogeneity. There were no such focal differences in mRNA distribution.

\section{Discussion}

CD44s and 'CD44v mRNA are elevated specifically in regions of epithelial accumulation and invasion in colonic adenomas and carcinomas, confirming observations with other techniques including RT-PCR ${ }^{7}$ and immunohistochemistry, ${ }^{8}$ that CD44 gene activity is increased in malignancy. The theoreti- cal possibility that increased numbers of reactive and inflammatory "normal" cells arriving in the tumour might have contributed to the differences in CD44v expression between normal and cancer tissue observed with RT-PCR, is therefore refuted. Conversely, the interpretation that abnormal CD44 activity could be a clinically useful marker for malignant cells in diagnostic biopsy and fluid samples is strengthened by these converging lines of evidence showing that the abnormal and elevated CD44 expression revealed by PCR is a direct product of the cancer cells.

These experiments were deliberately designed so that the CD44s probe would hybridise maximally with tissue transcripts which did not contain any CD44v exons (fig 1). The CD44s probe was amplified by PCR, using a CD44s template derived from peripheral blood lymphocytes, which did not of course contain any CD44v exons. Hence, the probe would not bind completely to the mRNA if CD44v elements were inserted in the target making hybridisation less efficient and such a probe would be detached in the high stringency washing conditions. Conversely, $\mathrm{CD} 44 \mathrm{v}$ probes were designed to span the entire variant region without overlapping the flanking CD44s region (fig 1) and would thus
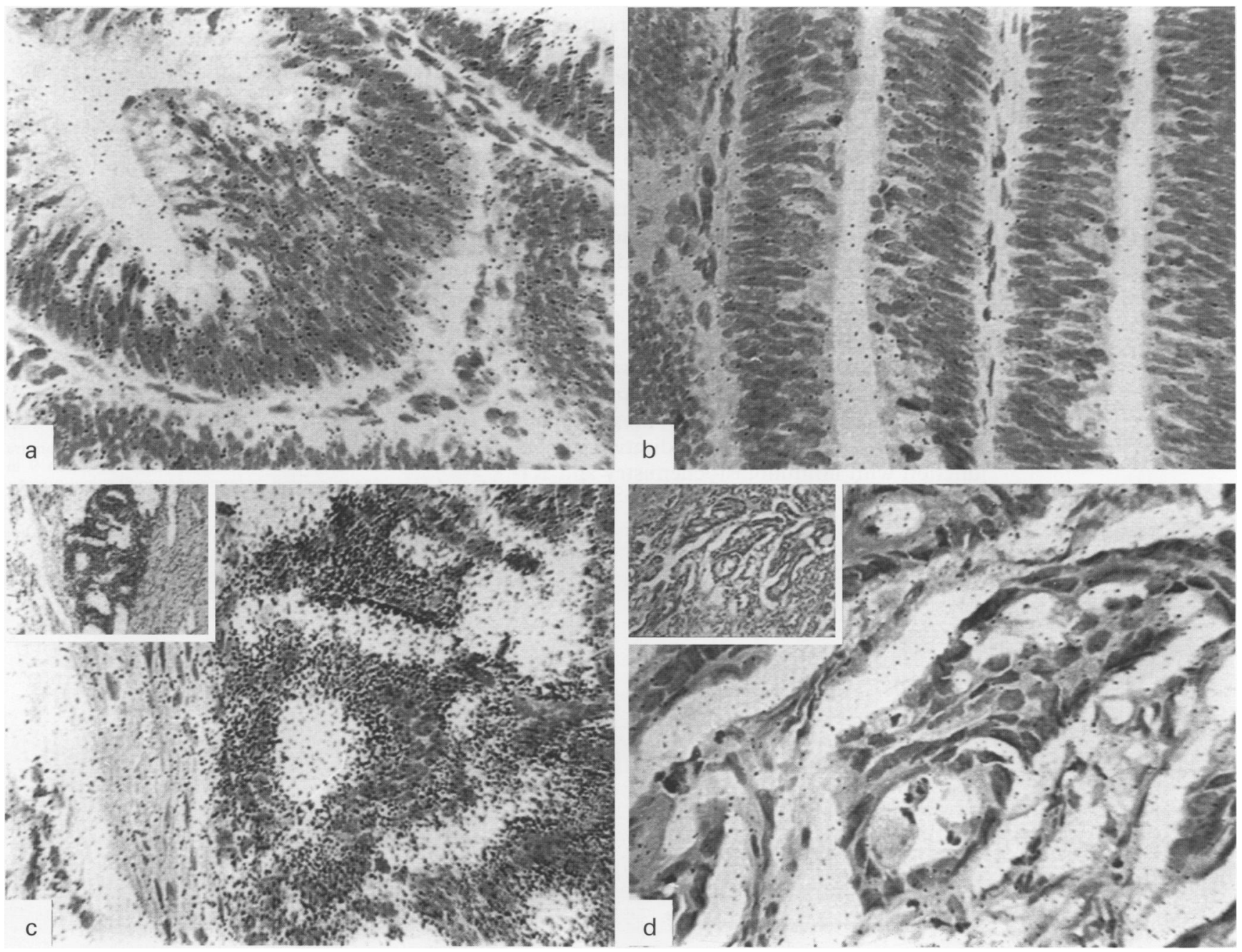

Figure 4 Frozen sections of colonic adenoma (a) and (b) hybridised with CD44s antisense and sense riboprobe, respectively. Plates (c) and (d) show colonic carcinoma hybridised with CD44s antisense and sense riboprobe, respectively, with a lower power magnification inset. (Magnificiation $\times 440$.) In both cases signal can be seen to be increased over neoplastic cells, compared with normal colonic mucosa. The most striking increase occurred over carcinoma cells. 
only remain annealed to transcripts containing partial or full length CD44v region encoded by all the variant exons. From this it can be understood that the increases observed in CD44s and CD44v containing transcripts in tumours are true readings of the quantity and distribution of transcripts containing the corresponding, homologous, elements in human tissues. It should be realised, however, that the information obtained so far does not convey any knowledge of the composition and location of transcripts which contain less than the full complement of variable region exons. For this, further studies with probes for individual exons would be required. From the sizes of RT-PCR products obtained from normal tissues and the in situ hybridisation data given above, it would seem that the production of high molecular weight transcripts containing all the variant exons is a rare event in the cells of a nonneoplastic adult tissue.

The relations between the tissue distributions of mRNA transcripts and of peptide epitopes encoded by the CD44 exons, revealed by the parallel application of in situ hybridisation and immunohistochemical techniques on matched samples of normal and neoplastic tissue from the same patients, are intriguing. In general, the quantities and distibutions of CD44 mRNA and proteins were similar, but they did not always correspond. Further analysis may reveal important information about the relative turnover of CD44 mRNA and proteins in normal and malignant cells. For instance, the presence of abundant variant mRNA in some areas of carcinomas which do not stain with CD44 antibodies is curious and may reflect derangements in translation or posttranslational processing of abnormal transcripts, or both. ${ }^{15}{ }^{16}$ At present these apparent inconsistancies remain unexplained, but they may provide important clues to the kinetic relations between $\mathrm{CD} 44$ gene transcription and translation in normal and neoplastic cells. The findings presented in the current study indicate that the complex activities of this large and multifunctional gene are most suitably analysed by using in situ hybridisation in conjunction with immunohistochemistry and RTPCR.
We appreciate valuable advice and discussions about in situ hybridisation with Ann Trezise during the conduct of this work Andrew Graham for image analysis and Kazuhiro Yoshida for valuable comments. We also thank Susannah Crowley and Helene Mellor for technical assistance and Linda Summerville for help in preparation of the manuscript. Dr E C Butcher kindly provided us with the Hermes 3 monoclonal antibody. The work was supported by a research contract between Boehringer Mannheim GmbH and Oxford University.

1 Gunthert U. Adhesion in leukocyte homing and differentiation. Curr Top Microbiol Immunol 1993;184:45-62.

2 Haynes BF, Telen MJ, Hale LP, Denning SM. CD44-a molecule involved in leukocyte adherence and T-cell activation. Immunol Today 1989;10:423-8.

3 Screaton GR, Bell MV, Jackson DG, Cornelis FB, Gerth U, Bell JI. Genomic structure of DNA encoding the lymphocyte homing receptor CD44 reveals at least 12 alternatively spliced exons. Proc Natl Acad Sci USA 1992; 89:12160-4.

4 Cooper DL, Dougherty G, Harn H-J, Jackson S, Baptist EW, Beyers J, et al. The complex CD44 transcriptional unit: alternative splicing of three internal exons generates unit: alternative splicing of three internal exons generates 1992;182:569-78.

5 Matsumura Y, Tarin D. Significance of CD44 gene products for cancer diagnosis and disease evaluation. Lancet 1992;340:1053-8

6 Matsumura Y, Hanbury D, Smith J, Tarin D. Non-invasive detection of malignancy by identification of unusual CD44 gene activity in exfoliated cancer cells. $B M \mathcal{F}$ 1994;308:619-24.

7 Wielenga VJM, Heider K-H, Johan G, Offerhaus A, Adolf GR, van den Berg FM, et al. Expression of CD44 variant prot van den Berg FM, et al. Expression of CD44 variant proteins in human colorectal cancer is re

8 Heider K-H, Hofmann M, Hors E, van den Berg F, Ponta H, Herrlich P, Pals ST. A human homologue of the rat metastasis-associated variant of CD44 is expressed in colorectal carcinomas and adenomatous polyps. $\mathcal{F}$ Cell Biol 1993;120:227-33.

9 Kaufmann M, Heider K-H, Sinn H-P, von Minckwitz G, Ponta $H$. CD44 variant exon epitopes in primary breast cancer and length. Lancet 1995;345:615-19.

10 Gunthert U, Hofmann M, Rudy W, Reber S, Zoller M, Haubmann I, et al. A new variant of glycoprotein CD44 confers metastatic potential to rat carcinoma cells. Cell 1991;65:13-24.

11 Mackay CR, Terpe H-J, Stauder R, Marston WL, Stark H, Gunthert U. Expression and modulation of CD44 variant isoforms in humans. $\mathcal{F}$ Cell Biol 1994;124:71-82.

12 Simmons DM, Arriza JL, Swanson LW. A complete protocol for in situ hybridisation of messenger RNAs in brain and other tissues with radiolabeled single-stranded RNA other tissues with radiolabeled
probes. $₹$ Histotech $1989 ; 12: 161-81$.

13 Jalkanen S, Jalkanen M, Bargatz R, Tammi M, Butcher EC. Biochemical properties of glycoproteins involved in lymphocyte recognition of high venules in man. $\mathcal{F}$ Immunol 1987;141:1615-23.

14 Borgya A, Woodman A, Sugiyama M, Donie F, Kopetzki E, Matsumura Y, Tarin D. Isolation and characterisation of antibodies which specifically recognise the peptide encoded by exon 7 (v2) of the human CD44 gene. 7 Clin Pathol: Mol Pathol 1995;48:M241-M250.

15 Matsumura Y, Sugiyama M, Matsumura S, Hayle AJ, Robinson P, Smith JC, et al. Unusual retention of introns in CD44 gene transcripts in bladder cancer provides new in CD44 gene transcripts in bladder cancer provides new diagnostic and clinic

16 Yoshida K, Bolodeoku J, Sugino T, Goodison S, Matsumura $\mathrm{Y}$, Warren BF, et al. Abnormal retention of intron 9 in CD44 gene transcripts in human gastrointestinal tumors. Cancer Res 1995;55:4273-7. 